\title{
The Significance of Nirvana in Fire's Spirit of Loyalty
}

\author{
Li Xue ${ }^{1, a}$ Liu Yixin ${ }^{2, b}$ Chen Haiyan ${ }^{3, c^{*}}$
}

\author{
${ }^{1}$ School of Literature and Journalism, Xihua University, Chengdu, Sichuan, China \\ ${ }^{2}$ School of Literature and Journalism, Xihua University, Chengdu, Sichuan, China \\ ${ }^{3}$ School of Literature and Journalism, Xihua University, Chengdu, Sichuan, China \\ a18722965026@163.com \\ b1014534210@qq.com \\ c*490395622@qq.com (Corresponding Author)
}

\begin{abstract}
The novel Nirvana in Fire tells a story about Mei Changsu's undying pursuit of justice, self-sacrifice, self-sacrifice, selflessness and mutual help, which accords with the core socialist values of justice, patriotism, honesty and friendship. The contemporary spirit of loyalty and righteousness in Nirvana in Fire has a positive impact on the establishment of correct values, and is conducive to the establishment of justice, patriotism, and good manners of honesty and friendship.
\end{abstract}

Keywords: Nirvana in Fire, loyalty, justice, patriotism, honesty and friendship

\section{《琅哪榜》忠义精神的现实意义 \\ 李雪 ${ }^{1, a}$ 刘艺馨 ${ }^{2, b}$ 陈海燕 ${ }^{3, c *}$}

${ }^{1}$ 西华大学文学与新闻传播学院, 成都, 四川, 中国

${ }^{2}$ 西华大学文学与新闻传播学院, 成都, 四川, 中国

${ }^{3}$ 西华大学文学与新闻传播学院, 成都, 四川, 中国

18722965026@163.com

b1014534210@qq.com

c*490395622@qq.com（通讯作者）

\section{摘要}

小说《琅躯榜》讲述了梅长苏忍辱负重昭雪冤情的故事, 文中表现的矢志不渝追求正义、舍已为人、克己奉公, 赤诚无私、互帮互助的忠义精神与社会主义核心价值中倡导的公正、爱国、诚信友善相契合。《琅躯榜》中具 有当代价值的忠义精神，对建立正确的价值观具有积极影响，有利于树立公正理念、培养爱国情怀、营造诚信 友善的良好风尚。

关键词: 《琅躯榜》, 忠义精神, 公正, 爱国, 诚信友善

\section{1. 前言}

中华优秀的传统文化是社会主义核心价值观的 深厚沃土, 深度挖掘和创造性的继承具有时代价值的 传统文化对弘扬社会主义核心价值观具有重要意义。 网络小说的成就离不开传统文化的涵养, 因此, 网络 小说更应该扎根在中华优秀传统文化的土壤中, 将中 华文化的精髓融入精彩的故事中, 以艺术的方式传承
中华传统文化。《琅哪榜》在传承优秀传统文化，传 播正能量, 表现时代精神等方面具有典范意义, 其中 具有现实意义的忠义观与社会主义核心价值观相契 合。

\section{2. 忠义精神溯源}

忠义精神作为东方特有的伦理道德准则, 是中华 优良传统文化的重要组成部分, 作为民族精神的集中 
体现, 它渗透到中华民族的各个领域, 是中华民族生 生不息的精神动力和源泉。

\section{1 忠: 尽己之力至公无私的责任}

“忠” 是尽心、尽力、内心情感、外在行为的统 一, 它有两层含义。一是, 忠信之忠, 指内心的诚敬 之意, 是人际关系的准则。《说文》中说 “忠, 敬也, 从心, 中声”, 意思是尽己之心, 与人为敬为忠, 它 与现代意义上的 “诚心、衷心” 意义相同。二是, 为 民之忠, 指热爱祖国, 包括了个体对国家的责任和义 务。如 “临患不忘国, 忠也”; (《左传)。在国家危难 之际, 为民应顾全大局, 以集体利益为重, 即使牺牲 自己, 也要义不容辞的做有利于国家利益的事, 这就 是忠。“忠” 作为一个历史概念, 其中诚信和爱国的 含义, 仍然与当代道德规范相契合。

\section{2 义: 照亮历史的道德之光}

“义” 作为五常之一, 是华夏民族普遍认同的价 值范畴, 是超乎个人利益的道德准则, 体现了传统社 会的正义。一千多年来, 义的观念在人们的思想中占 有非常重要的地位。尽管义没有权威的定义, 但自古 以来人们对其意义是心领神会的。如肯定义薄云天, 情义千秋、舍生取义、大义凛然等是义, 假公济私、 忘恩负义、大义灭亲等是不义。正是因为义的的内涵 复杂多变, 才使得它更富有弹性, 蕴含更丰富的思想 内容。“义” 主要有二层含义: 一是, 义与善、美同 意。“义, 己之威仪也。从我从羊” (《说文》)。义字 从羊, 羊在六畜主为膳, 其肉为食, 其毛为服, 其性 温良, 故 “美”、“善” 等字均从羊。所以, 义代表着 人际交往中的友谊和追求美好、善良等需要。二是, 与利相对而言, 所谓 “言义必及利”。这里的义涉及 到如何处理利益得失问题, 这也是儒家最重视和强调 的问题。如 “不义而富且贵, 于我如浮云” (《论语・ 述而); “君子喻于义, 小人喻于利。”(《论语・里仁》); “夫仁人者, 正其义不谋其利, 明其道不计其功” (《汉 书・董仲舒传》)。可见, 对于孔孟儒家来说, 一个仁 义君子, 在面临个人利益得失时, 不应一味追求个人 利益的满足而不择手段。而是应该慎重考虑和反思, 以集体利益为主, 以适宜人类公平道义的方式解决问 题, 尽力维护人类共同的利益和公共福祉的价值准则。 甚至在生存和道义发生冲突时, 应舍生取义切勿苟且 偷生。正如孟子曰: “生, 亦我所欲也; 义亦我所欲 也, 二者不可得兼, 舍生而取义者也。” 人之所以为 人, 正因有 “义”。数百年来, 家国情怀深深植根于 中华民族的灵魂和血液之中, “义” 影响着个人乃至 整个国家的成败。

\section{3 忠义：中国人立身处世的基本准则}

“忠” 和 “义” 作为传统民族精神的重要部分, 在某些方面具有相同的价值追求。后世所提出的忠义 精神正是综合上述忠和义的含义发展而成的一个道
德概念。忠一忠诚、忠信、忠于国家、忠于人民, 为 赤诚无私之意。义即公平正义、道义, 家国大义、奉 献, 对理想信念的追求。所谓忠义乃是一种临患不忘 国, 视死忽如归的爱国精神; 是尽心竭力、恪尽职守、 诚信友善的高尚品德; 是勇敢追求心中正义的赤子情 怀。可见, 新时代的忠义思想是一种完全积极的具有 正确价值导向的思想内涵, 是值得提倡和赞扬的道德 理念。

\section{3. 《琅㑚榜》“忠义精神” 的表现}

《琅哪榜》以复仇为主线, 讲述了 “麒麟才子” 梅长苏克服艰难险阻拨开重重迷雾, 昭雪冤情, 扶持 明君上位的故事。小说中个体对公平正义的追求, 人 物之间的兄弟情和家国义体现了现代忠义精神的价 值内涵。

\section{1 矢志不渝追求公平正义}

《琅㑚榜》以除奸报仇为结局, 展现了中国自古 以来 “惩恶扬善” 的道德追求, 鲜明的表达了 “善有 善报, 恶有恶报” 的传统观念。梅长苏作为寻求正义、 公道的使者, 他的活着就是为了昭雪冤情, 这种勇敢 追求正义的赤子情怀体现了现代意义上的忠义精神。 梅长苏是赤焰军统帅林烣之子, 天资聪颖、英勇无畏、 满怀赤子之心, 充满理想和抱负。他本该有一个光明 的未来, 然而因赤焰军势力过大, 再加上奸人诬陷, 使得全军上下葬身梅岭之地, 林殊幸运躲过一劫, 却 深受火寒之毒。他带着七万军士的冤魂重生, 为了声 张正义, 十三年来忍辱负重, 养精蓄锐, 从血气方刚 的林殊化身为身残䇔弱的梅长苏重新归来。梅长苏是

《琅哪榜》中最复杂的人物, 他即是肩负大义的谋士, 又是拨弄风云、老谋深算的谋士。但他始终坚守忠义, 实现了复仇的最终目标一社会正义。

梅长苏追寻正义的背景是在一个架空的封建社 会一梁国。封建政治话语中, 皇权就是至高无上的权 威, 想要在如此环境中寻求正义实属艰难, 再加上这 件冤案关系着皇帝的绝对权威。普天之下, 莫非王土, 这就使得他追求正义的道路充满黑暗, 艰难坎坷。梅 长苏作为江左盟盟主, 本可以远离朝堂, 过闲适的生 活, 在山水田园中安稳渡过为数不多的岁月。但他身 上背负昭雪冤情的重任, 他心中有大义, 这使得他毅 然决然入仕玩弄被人唾弃的阴诡之术。在权力斗争中, 梅长苏借助 “江左梅郎, 麒麟才子, 得之可得天下” 的江湖传言成为权利斗争的中心人物。他一边为誉王 出谋划策, 实则是为了削弱他方力量, 为靖王扩展势 力, 充分发挥他作为谋士的智慧和担当。在追寻正义 途中, 尽管梅长苏的目的无可指责, 但也不能掩盖其 手段的卑劣。他把朋友萧景睿当做旗子, 使得家破人 亡。他把童路的家人留在琅㑚榜, 实则是为了防止童 路不忠。在救赤焰救人卫峥时, 梅长苏显示了作为谋 士的寡断, 他本可以救出卫峥, 却为了顾全大局犹豫 了。曾经才华横溢、意气风发的善良林殊变成精于算 
计、容颜尽改的谋士梅长苏; 曾经充满义气可以为朋 友两肋插刀的林殊如今变得冷漠无情, 他陷入了内心 伦理道德的煎鰲。

正义和罪恶, 光明与阴暗, 善良和阴险的复杂纠 葛加剧了梅长苏寻找公平正义的艰难程度。但他始终 没有放弃，他始终追求心中的公平正义，誓死还七万 赤焰军一个公道。他曾受到挚友靖王的冷漠和质疑, 遭受谢玉暗杀、夏江的步步威胁, 以及病痛的折磨。 外在的生命威胁和内心的折磨终究没有打败梅长苏, 更没有阻断他前进的决心和斗志。经过十几年的筹划 与布局, 他最终为自己和七万赤焰军冤魂平反, 让艰 险恶毒之人受到应有的惩罚, 还清白于天下、还正义 于人间、还公道于人心, 梅长苏宁愿舍生取义也不荷 且偷生, 无愧于忠义。

\section{2 权谋背后的家国情怀}

《琅㑚榜》无时无刻不在表现深厚浓重的家国情 怀。梅长苏在复仇之路上, 并没有陷入仇恨的逻辑中, 相反, 他显现出了正义的一面, 在他的形象中, 更多 展现的是家国大义。他为了平反推崇靖王上位, 实则 也是为了天下苍生。他始终担心梁国的发展, 心系黎 明百姓, 希望国家能够恢复清明政治, 为此, 他在拨 去太子誉王心腹时, 不顾私心换上了一批方正贤良之 士, 为梁国未来的发展打下基础。小说结尾处, 梁国 受到外敌入侵, 国家处于危难之际, 本该安享余生的 梅长苏毅然决然重披战甲, 不顾一切慷慨赴死。梅长 苏不妥协于现实䇔弱的身体, 他活着的目的是为赤焰 军昭雪冤情, 为天地立心, 为生民立命, 为往圣继绝 学, 为万世开太平, 他宁愿战死沙场也不愿苟延性命 于山水之间。十几年的翻云覆雨, 一切都发生了改变, 只唯一不变的是一颗赤子之心, 永生不死。梅长苏身 上体现着传统士大夫勇于担当、不畏艰辛、不怕牺牲、 为国家出生入死的忠义精神。除了梅长苏以外, 家国 大义无时无刻不体现在《琅㑚榜》中。靖王坚毅隐忍, 重情重义, 坚持原则, 赤子之心坚若磐石, 以天下大 事为己任, 出于自己的政治理想, 不愿天下落入只要 权力不管安危的兄弟手中。蔡权和沈追有济世报国之 心, 有公正廉明之举, 辅佐靖王重振梁国。言侯在个 人仇恨和国家利益面前选择以家国为主。他们内心世 界都是一样的, 家国二字永远是最重要的。可以说, 家国情怀是《琅㑚榜》的核心和生命力所在。

\section{3 机关算尽之下的情义干秋}

《琅㑚榜》中歌颂了友善和真挚的情义。梅长苏 因为复仇, 变成曾经痛恨的阴论谋士, 但他内心的善 良自始自终都存在, 他对自己的手下和身边的朋友, 都表现出真挚的善意。他救下飞流, 像亲弟弟一样爱 护; 帮助言侯爷摆脱困境, 巧设妙计化解言家父子的 心结, 成全亲情; 帮助聂锋与夏冬想见, 成全爱情。 他是一个谋士, 但他从不伤害无辜之人。他的友善使 得手下和朋友对他尽心竭力。他为自己隐瞒身份以及
利用萧景睿对他的情义感到深深地愧疚, 在萧景睿去 大楚途中, 派人暗中保护他。他动员江湖力量救出卫 峥。帮助聂锋与夏冬想见, 成全爱情。他是一个谋士, 但他从不伤害无喜之人。他的友善使得手下和朋友对 他尽心竭力。小说中重情重义的萧景睿也一直感动着 读者, 他是小说中最重情义的悲剧人物, 他温厚宽容, 富有正义感, 颇具责任心。他永远真诚对待每一个人, 即是得不到回报, 依然永葆初心。

《琅㑚榜》虽是以复仇为主线, 但不同于其他复 仇爽文, 海宴更重视对情义的描写。围绕梅长苏, 作 者刻画了一个个情义深重的人物。蒙挚作为梅长苏的 朋友, 对他肝胆相照、两内插刀, 始终义无反顾的支 持和帮助他寻求正义。林殊和靖王是从小的挚友, 是 可以同生死共患难的兄弟, 他们的兄弟情远远超过他 人之间的情义范畴。靖王始终坚信林殊不会叛乱, 林 殊永远为靖王考虑, 他选择以梅长苏的身份忍辱负重, 保住景琰那份赤子之心。从地狱重生的梅长苏和从东 海归来的靖王经过十三年心境的变化, 早已不是当初 的少年。梅长苏肩负重任, 靖王忧心忡忡。他们在痛 苦中不断磨研自己。面对昔日挚友的猜疑甚至鄙夷, 梅长苏选择忍辱不发。权力斗争中, 梅长苏拉拢一切 可以借助的力量, 尽心竭力帮助靖王成功。地道中, 梅长苏与靖王无数次畅谈到深夜, 大到朝堂争斗, 小 到黎民百姓, 梅长苏一步步辅佐他成为更贤明的君主, 他们也开始有了朋友之间的信任。小说第六十章火寒 奇毒和第六十一章莫逆之交是最打动人的地方, 作者 用了一系列动作描写和心理描写刻画了一副震慑人 心的场面。在苏宅门口, 他 “突然勒住缰绳, 动作之 猛, 使得胯下坐骑长嘶一声, 前蹄扬起, 马身几乎直 立, 再落下地时, 景琰的手一松, 整个身体从马背下 摔落下来, 重重砸在地上” [1]，他犹豫了，他的 心脏像被小刀来回扎过, 他不能接受自己是踩着朋友 咬牙支撑的背脊走到今天。他的内心即是欣喜又是痛 苦。从林殊到梅长苏再回到林殊, 他们的情义更加深 厚。从误解到改变偏见, 最后珍视对方。《琅哪榜》 从阳刚的侧面反应了男人之间的义薄云天、情义千秋。

“一卷风云琅㑚榜, 囊尽天下奇英才。” 《琅躯 榜》中各位英才对伸张正义、舍身取义、家国大义、 兄弟情义身体力行的不解追求, 体现了现代意义上的 忠义精神内涵。

\section{4. 《琅㑚榜》忠义精神的现实意义}

随着社会的发展, 竞争更加激烈, 面对社会中出 现的拜金主义, 个人利已主义, 是非、善恶、美丑混 淆, 弘扬忠义精神中表现的对正义的追求, 以家国大 义为重, 待人诚实友善的文化内涵有助于推进社会主 义核心价值观的建设。

\section{1 树立 “公正” 理念}

《琅㑚榜》中体现的“矢志不渝追求正义”和 “惩 恶扬善” 的精神与社会主义核心价值观中倡导的 “公 
正”价值理念是相联的。社会主义核心价值观中的公 正是对社会和个人的要求。为国，应建立公正的方针 政策。为官，应以公正为标尺，惩恶扬善。为民，应 以正义为初心, 行正义之举。然而随着经济的快速发 展, 社会中出现了很多不公不正之举, 本该铁面无私 的官员贪污腐败、知法犯法, 以损害百姓利益成全自 己私利, 不守官德。现实生活的人们急于求成, 不择 手段谋求利益, 至公平正义于脑后。见义不为的现象 屡次发生, “见义勇为流血流泪” 被大众接受, “事不 关已高高挂起”已经成为很多人的处世哲学。遇到不 公, 人们选择冷漠, 遇到不义, 人们选择绕道退缩。 在正义感不断缺失的社会, 忠义精神中追求公平正义 的价值内涵具有借鉴意义, 弘扬忠义精神有利于树立 公正的理念。

\section{2 培养爱国情怀}

《琅㴬榜》中体现的“家国大义” 情怀与社会主 义核心价值观中倡导的 “爱国” 价值理念是相联的。 全球化时代，各国之间的交流日益频繁，不同的文化 价值立场随着网络不断传播。全球化和现代化不仅影 响了个人的生活和思想, 也加剧了弘扬爱国主义的困 难, 削弱了爱国主义情感。全球化浪潮中, 不同文化 之间相互冲击、融合、渗透, 但文化的全球化并不是 均衡发展的。西方国家以及亚洲某些国家为了获得最 大程度的利益, 不断对我国实施文化侵略, 通过电影、 电视等媒介不断宣传他们的精神产品, 恶意歪曲中华 民族精神, 用中国元素反向推销他们的意识形态。近 年来, 不立足民族文化, 表现个人英雄主义的非中国 化主题的文艺作品频频出现。如 2016 年上映的《大 鱼海棠》中, 椿为了鲲的生命不惜牺牲全族的利益, 这与传统民族精神中杀身成仁、公而忘私的思想是相 悖的。今年出的《姜子牙》中, 姜子牙为一人弃苍生 的价值观与现代社会强调国家利益高于个人利益的 思想理念相悖。可见, 西方价值观的严重侵袭对我国 文化产生了消极作用, 它不断侵浊传统文化、民族精 神, 使得国人降低对祖国的自豪感。它们试图侵占中 国文化市场, 通过文化扩张和意识形态渗透达到文化 霸权的目的, 从而谋求世界霸权的企图。在这样的条 件下, 爱国精神显得尤其重要, 我们必须要夯实中华 传统文化中的文化自信和自觉, 从根本上增强国人的 骨气和底气, 并自觉内化为爱国情怀。《琅㑚榜》中 以国家利益为主的奉献精神具有借鉴意义, 舍已为人、 克己奉公的思想是身处现在社会所需要遵循的优良 品德。

\section{3 倡导诚信友善的良好风尚}

诚信友善的品质是公民基本的道德标准和规范, “诚信友善包括自尊自律、诚实守信, 文明礼貌、宽 和待人, 孝亲敬长、有感恩之心, 热心公益、志愿服 务四方面的内容。” [2] 坚持诚信友善能促进和谐的人 际关系, 促进社会文明的发展。随着社会竞争的加剧, 快节奏的生活方式使得人的精神压力越来越大, 人与
人之间隔绝、冷漠、虚伪成为一种普遍的现象。再加 上在网络社会中, 信任常常陷入现实的欺骗困境中, 使得人际交往中的不信任感愈加强烈。近年来出现的 “微商”、“电信计骗”、“网络信息不断反转”、“主播 带假货” 等事件不断摧毁人与人之间的信任, 把诚信 践踏的一无是处，使得人们更不愿意相信任何人。自 私、虚伪使得现代人越来越浮躁, 面对人际交往问题 时, 往往不能互相理解, 不能和睦的解决问题, 反之 采用极端的行为。在这个信用危机时代, 《琅㑚榜》 忠义精神中对人尽心竭力、真诚无私、信守承诺, 鼓 励人与人之间互相关心、互相帮助的优良品质有助于 更好的倡导人们遵守诚信友善的道德准则。

\section{5. 结论}

中华优秀传统文化是中华民族的文化根源和精 神命脉。它所体现的思想、人文精神和道德规范, 是 中华民族思想和精神的核心，是中国人民安身立命、 自强不息的精神家园。培育社会主义核心价值观必须 从传统文化中汲取丰富营养, 离开了传统文化的滋养, 社会主义核心价值将会变成无源之水、无本之木。《琅 躯榜》中体现的忠义精神展现了中国传统文化和儒家 思想的睿智光芒, 与当前弘扬的社会主义核心价值观 相辅相成, 传承具有当代价值的忠义精神, 能更好的 践行社会主义核心价值观。

\section{项目基金}

本文为西华大学引进人才项目《现实题材网络文 学创作、传播及批评研究》（w212247）阶段性成果的 阶段性成果之一。

\section{REFERENCES}

[1] Hai, Y. (2014) Nirvana in Fire. Sichuan Literature and Art Publishing House, Chengdu.p756

[2] Tan , S , k. ( 2018 ) On the Cultivation and Improvement of Teenagers' Integrity and Friendship Quality .J. Southern Journal,(04):94-96.

[3] Xu,M,X. (2015)Judging from the past and Resonating with Human Nature-Interpreting the characters in Nirvana in Fire from the Perspective of Jungian psychology. J. Arts, (6) : 44-46.

[4] Shen, C,H; Su, T,P. ( 2017 ) The Spatial Narrative of Nirvana in Fire and Chinese Artistic Spirit. J. Chinese Literature Studies, (01):20-23.

[5]Zhao,B.(2019)Research on Guan Gong culture and it s Contemporary Value.C.Xi'an University of Technology.

[6]Guo, J,N. (2018)Cultural Self-Confidence and Contemporary China .J. Peking University Journal (Philosophy and Social Sciences Edition), 55 (02): 
57-61.

[7] Lu,W,M;Sun,Z,H.(2017) On Xi Jinping's Thoughts on Cultural Self-Confidence.J. Journal of Beijing University of Technology , (05):50-56.

[8] Zheng,X,X. (2016)On Guangong and Guangong Cultures.J. Central Plains Cultural Studies, (02): 98-104. 